\title{
ATOMIZATION OF LIQUID DROPLETS IN A CONVECTIVE GAS STREAM
}

\author{
A. A. RANGER* \\ Aerospace Sciences Laboratory, Purdue University, Lafayette, Indiana, U.S.A. \\ and \\ J. A. NICHOLLS $\dagger$ \\ Gas Dynamics Laboratories, The University of Michigan, Ann Arbor, Michigan, U.S.A.
}

(Received 4 August 1970 and in revised form 22 March 1971)

\begin{abstract}
New experimental results are reported for the atomization of liquid droplets by a high-speed air stream. A series of experiments are described in which water droplets, ranging in diameter from 1000 to $2700 \mu$, were introduced into the test section of a shock tube and allowed to interact with the convective flow established by the passage of a propagating shock front. A rotating drum camera system was employed to obtain a collection of streak photographs of the atomization process from which the breakup time, the breakup distance, and the ultimate atomized particle size were determined. The experiments covered a Weber number range given by $0.7 \times 10^{3} \leqslant W e \leqslant 85.5 \times 10^{3}$.
\end{abstract}

\section{NOMENCLATURE}

$a_{1}$, speed of sound in driven section;

$a_{2}$, speed of sound in convective flow;

$C_{D}$, drag coefficient:

$D_{0}$, initial droplet diameter ;

$M_{S}$, incident shock Mach number

$$
\left(=U_{s} / a_{1}\right)
$$

$M_{2}$, convective flow Mach number

$$
\left(=U_{2} / a_{2}\right)
$$

$P_{1}, \quad$ driven section initial pressure;

$q_{2}$, convective flow dynamic pressure

$$
\left(=\frac{1}{2} \rho_{2} U_{2}^{2}\right) \text {; }
$$

Re, Reynolds number $\left(=\rho_{2} U_{2} D_{0} / \mu_{2}\right)$ :

$t$, time:

$t_{b}$, breakup time: time to accelerate to $0.6 U_{2}$ :

$T, \quad$ dimensionless time $=\left[U_{2} / D_{0}\right]$ $\left[\rho_{2} / \rho_{l}\right]^{\frac{1}{2}} t$ :
$\bar{T}_{b}$, dimensionless breakup time

$U_{S}, \quad$ incident shock velocity;

$$
=\left[U_{2} / D_{0}\right]\left[\rho_{2} / \rho_{l}\right]^{\frac{1}{2}} t_{b} ;
$$

$U_{2}$, convective flow velocity;

$W e, \quad$ Weber number $=\rho_{2} U_{2}^{2} D_{0} / \sigma$;

$x$, displacement;

$\bar{X}, \quad$ dimensionless displacement $=x / D_{0}$;

$\mu_{2}$, convective flow viscosity coefficient ;

$\rho_{2}$, convective flow density;

$\rho_{l}, \quad$ droplet density;

$\sigma, \quad$ droplet surface tension;

$\tau$, time when droplet velocity $=0.95 \mathrm{U}_{2}$;

$\bar{\tau}, \quad$ dimensionless time $=\left[U_{2} / D_{0}\right]$

$$
\left[\rho_{2} / \rho_{l}\right]^{\frac{1}{2}} \tau \text {; }
$$

$\chi$, displacement when droplet velocity $=0.95 U_{2}$;

$\bar{\chi}, \quad$ dimensionless displacement $=\chi / D_{0}$.

\section{INTRODUCTION}

THE ATOMIZATION of liquids by a gaseous stream is a phenomenon having fundamental physical importance in a variety of engineering problem Sciences.

+ Department of Aerospace Engineering. 
areas. The applications of atomization are too numerable to mention here, but in general, they include all those situations in which it is highly desirable to convert, as rapidly as possible, the cohesive mass of a liquid droplet into a finely dispersed micromist composed of extremely small particles. Since the gas stream must perform a considerable amount of work on the droplets in order to break them up into small fragments, the atomization process can be regarded as a form of energy sink. It is this latter aspect of the atomization phenomenon which lends itself, for example, to the attentuation of blast waves propagating in a droplet laden atmosphere.

The fate of a droplet following its introduction into a convective gas stream is principally determined by the relative magnitudes of the forces tending to hold it together and those attempting to tear it apart $[1,2]$. If these forces are approximately equal to one another, then the drop will enjoy a state of equilibrium in which it will simply be accelerated intact up to the velocity of the convective flow. However, if the external disruptive forces exceed the internal restraining ones, then the droplet will no longer be in a state of equilibrium. Under these conditions, it will be broken up while simultaneously being accelerated by the gas stream. The disruptive forces are aerodynamic in origin and proportional to the dynamic pressure $q \propto \rho_{g} U_{g}{ }^{2}$ while the internal forces of restraint are, in the main, proportional to the surface tension pressure $P_{s} \propto \sigma / D$. A ratio of the dynamic pressure force to the surface tension pressure force, i.e. $W e=\rho_{g} U_{g}{ }^{2} D / \sigma$, is called the Weber number and its critical value, We crit, denotes the magnitude of this ratio at which the droplet will become unstable and breakup. According to a theory advanced by Hinze [3], $W e_{\text {crit }} \simeq \mathbf{1 0}$ for droplets of small viscosity, such as water, while for liquids of much larger viscosity, the theory predicts a value of $W e_{\text {crit }} \simeq 23$.

Several experimental investigations [4-8] have been conducted to determine the critical
Weber number and the breakup mechanism for a variety of liquid droplets of different diameter, density, viscosity, and surface tension. For droplets having initial diameters in the range of $100 \mu \leqslant D \leqslant 1000 \mu$, these empirical studies indicate that $5 \leqslant W e_{\text {crit }} \leqslant 25$; results which agree amazingly well with the predictions based on Hinze's theory. As one might intuitively expect, the largest experimentally obtained critical value of the Weber number corresponds to the shattering of the smallest liquid droplets having the highest viscosity. Furthermore, the photographs taken during the course of these experiments reveal that there are at least two fundamental modes of disintegration depending on the magnitude of the Weber number. When the Weber number is on the order of $W e_{\text {crit }}$ the droplets are observed to be flattened-out into lenticular shapes and then inflated, in the downstream direction, into a balloon or baglike structure which ultimately becomes unstable and collapses into a shower of smaller droplets. This is the so-called bag mode of atomization which has been carefully documented by Lane [5] and Hanson [6]. However, when the Weber number is approximately an order of magnitude larger than $W e_{\text {crit }}$, the mechanism of disintegration is observed to be drastically different. Under these conditions the droplets are atomized by what appears to be a surface stripping or shearing process. Photographs $[5,8]$ of this mode of breakup show that the droplet surface is rapidly eroded and swept downstream to form an extended wake of very tiny particles behind the drop. For intermediate Weber numbers, that is for the transition region defined by $W e_{\text {crit }} \lesssim W e \lesssim(10) W e_{\text {crit }}$, the disintegration process exhibits features [9] characterizing both of these modes.

While the earlier work concentrated on relatively low Weber number breakup, current attention is being directed toward an examination of the factors affecting the atomization process at extremely high Weber numbers: that is when $W e \gg W e_{\text {crit. }}$ This particular focus of interest is understandable when one considers 
the fact that the phenomenon has an important influence on the flight and integrity of a vehicle moving at supersonic speeds through a dropletladen atmosphere, and on the design of various high performance chemical propulsion systems currently under study. Thus, the purpose of this study was to examine in depth the atomization process as it occurs under such conditions and to determine, in so far as possible, the displacement, the breakup time, and the ultimate size of the tiny atomized liquid particles.

The data presented here represent an extension of the earlier studies undertaken by the authors and reported in [11]. These new experimental results were secured through modifications to the shock tube facility which made possible the exploration of a wider range of test variables. Thus, in the following sections, these new data are presented, analyzed, and compared with other relevant atomization investigations.

\section{EXPERIMENTAL INVESTIGATION}

Experimental facility

The droplet atomization experiments were conducted in a pressure driven shock tube facility which was especially designed for this purpose. A detailed description of the experimental apparatus is contained in [10]. All of the testing was confined to the convective flow region between the incident shock front and the interface separating the driver from the driven gas. The driven section of the tube was pressure sealed so that the initial air pressure in it could be pre-set and controlled through the use of a vacuum system and a bleed valve arrangement.

Water droplets of various sizes were created for the experiments by using a vibrating capillary technique. A full account of droplet production through the application of this method is contained in [10] and in a paper by Dabora [15]. Once generated, a steady stream of droplets was allowed to fall vertically through the windowed test section and into a collection container fastened to the bottom of the shock tube.

In the initial study, an image converter camera was the primary photo-instrumentation employed to capture a pictorial record of the atomization process. An assortment of the individual time-resolved shadow photographs taken with this camera are shown in [10] and [11]. The primary source of data in this study,

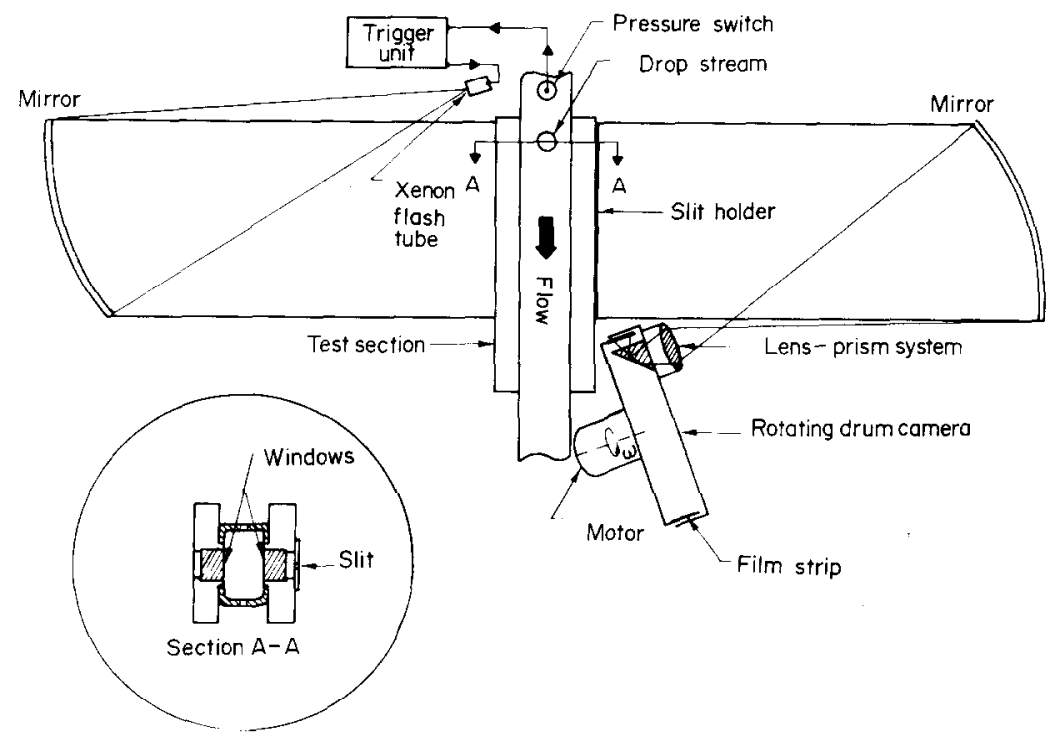

FIG. 1. Rotating drum camera arrangement. 
however, was the collection of streak photographs obtained by using a rotating drum camera arrangement shown in Fig. 1. As indicated in the diagram, the streak photographs of a single disintegrating droplet were taken by placing a narrow horizontal slit in the collimated light path. The time to free-fall a distance equivalent to the slit width was, in most cases, considerably longer than the breakup time and, therefore, if a drop was in the slit when the shock arrived in the test section, it did not pass from view before being completely shattered. The main advantage of this photographic technique over those previously employed in other studies is that the entire atomization process can be recorded on a single film strip.

\section{Experimental results and discussion}

A series of experiments were conducted on both large and small water droplets by subjecting them to a variety of convective flow conditions produced in the shock tube. The droplet diameter, the convective flow velocity, and the convective flow density were systematically varied to obtain results which covered a wide range of aerodynamic conditions. These results are for an incident shock Mach number range of $1.5 \leqslant M_{S} \leqslant 5.7$ in air, where the initial temperature was held constant and equal to $T_{1}=74^{\circ} \mathrm{F}$, and where the initial pressures were regulated between $1.5 \leqslant P_{1} \leqslant 14.7$ psia. Droplet sizes studied were in the range $1000 \mu \leqslant D \leqslant 2700 \mu$. The corresponding convective flow Mach number, Reynolds number, Weber, number, and dynamic pressure range were respectively,

$$
\begin{aligned}
0.6 & \leqslant M_{2} \leqslant 1.7,1.35 \times 10^{4} \leqslant R e_{2} \leqslant 41.3 \times 10^{4}, \\
0.7 \times 10^{3} & \leqslant W e_{2} \leqslant 85.5 \times 10^{3},
\end{aligned}
$$

and $10 \leqslant q_{2} \leqslant 325$ psia.

A vivid portrayal of droplet disintegration, under the conditions of high Weber number (i.e. $W e \gg W e_{\text {crit }}$ ), is given by the shadowgraph picture presented in Fig. 2. This is an enlargement of a polaroid photograph obtained with the image converter camera showing the atomiza- tion of a $2700 \mu$ water droplet in the convective flow produced by a Mach 3.5 incident shock wave in air where the initial pressure was equal to $P_{1}=1 \mathrm{~atm}$. The photograph was taken only $14 \mu \mathrm{s}$ after the incident shock made its contact with the forward stagnation point of the undisturbed drop. Under these circumstances, the flow relative to the drop is initially supersonic with a Mach number equal to $M_{2}=1 \cdot 5$, a convective flow velocity of $U_{2}=3070 \mathrm{ft} / \mathrm{s}$, and a dynamic pressure $q_{2}=325$ psia. The Weber number is equal to $W e=85.5 \times 10^{3}$.

As the incident shock passes the drop, it is suddenly and impulsively exposed to the high speed convective flow field set in motion by the propagating wave. Since the convective flow is supersonic in this instance, a stand-off bow shock is formed ahead of the droplet. This shock wave is visible in the photograph along with a vertical fiducial marker which was placed on the test section window to aid in the reduction of the displacement data. Immediately preceeding its subjection to the convective flow, however, the drop experiences a collision with the moving shock front. But the conclusion reached in several investigations $[6,11]$ is that the impact it receives from the collision is an insignificant element in producing the observed atomization. Rather, it is the aerodynamic pressure and viscous forces, acting respectively, in directions normal and tangential to the droplet surface, that are responsible for flattening-out the droplet against the flow and for stripping-away its surface to form the dense wake of micromist which is seen in the photograph. Thus, since the shock front interaction with the droplet is, by itself, inconsequential, the physical phenomena and the experimental results described here are considered to be equally valid for situations wherein the gas flow velocity relative to the droplet has been established by some means other than a propagating shock wave.

After being stimulated by photographs such as the one shown in Fig. 2, G. I. Taylor [16] and the authors [11] developed analytical models for the high Weber number disintegration by 


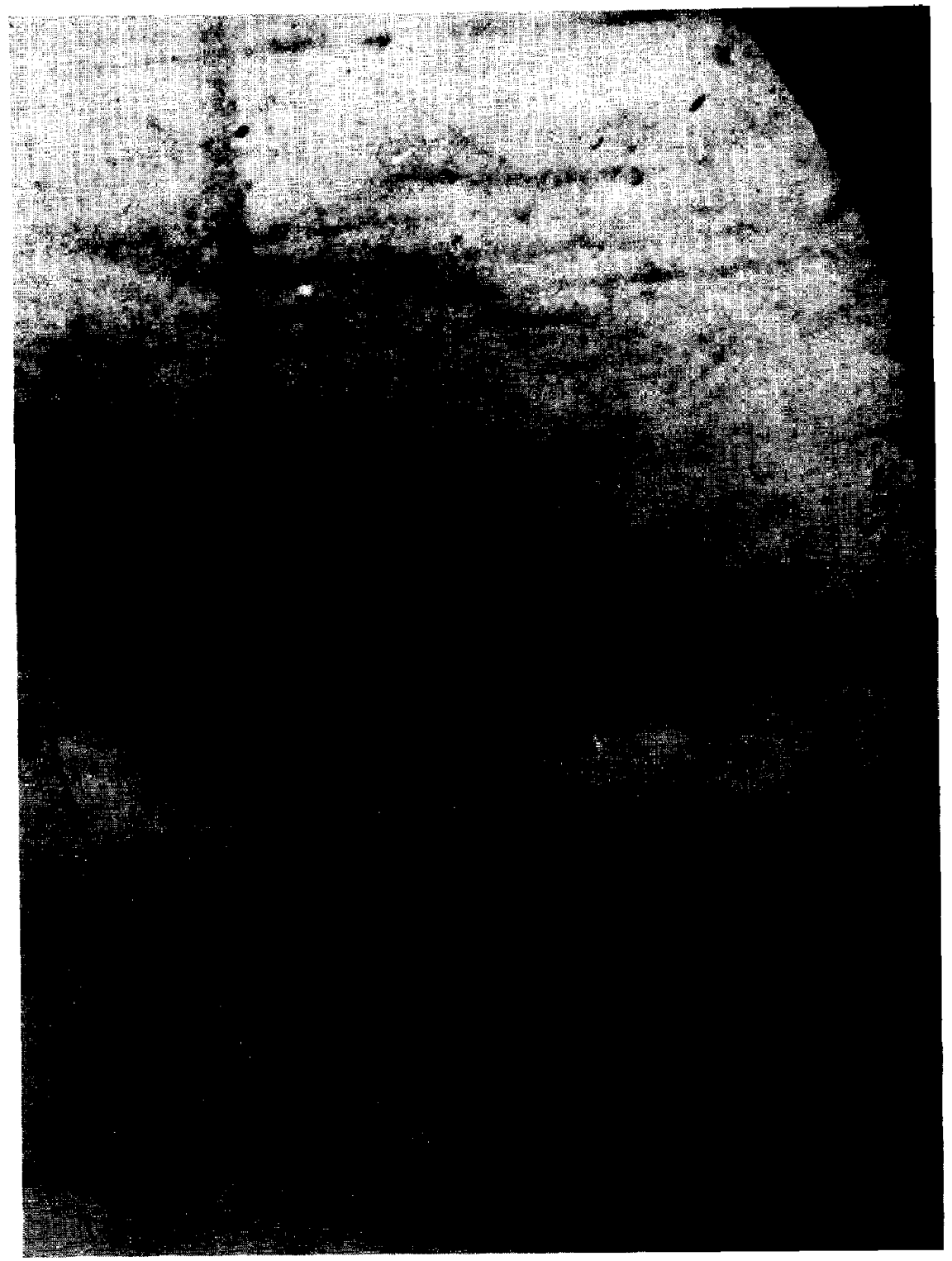

FIG. 2. Atomization of $2700 \mu$ water droplet. 


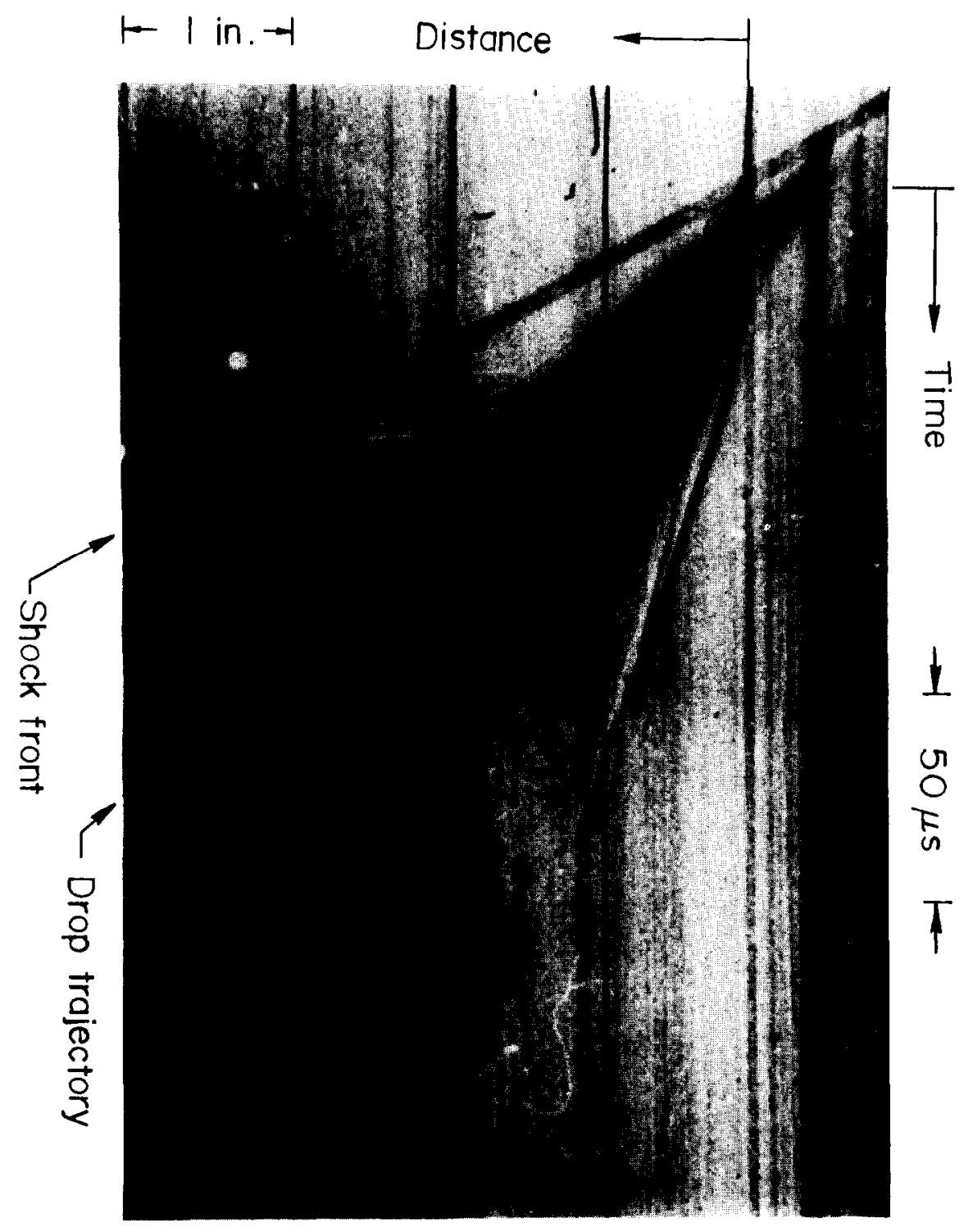

FIG. 3. Atomization of $1400 \mu$ water droplet. 
assuming that a droplet is atomized through a boundary-layer stripping mechanism. Through the use of these semi-empirical models it is possible to make approximate calculations of the atomization rate, the breakup time, and the distance a droplet is translated by the flow while simultaneously being disintegrated. However, while the appearance of the photographs, such as the one in Fig. 2, indicates that the initial portion of the atomization process results from a boundary-layer stripping mechanism, photographs showing the latter stages of the breakup $[10,14]$ are sufficiently complex enough to suggest that several breakup mechanisms may be at work simultaneously during this phase of the fragmentation.

While the image converter pictures provided valuable information regarding the droplet deformation history and the atomization mechanism, the task of gathering the data by taking photographs one at a time was rather tedious. Therefore, the rotating drum camera was used to make a series of photographs giving a continuous writing of the displacement and the breakup as a function of time. A typical example of the streak photographs obtained in this manner is shown in Fig. 3 where, as indicated on the figure, the abscissa and the ordinate are, respectively, the displacement and time axes. This photograph captures the disintegration of a $1400 \mu$ water droplet following its interaction with the convective flow established by a Mach 3.3 incident shock wave where the initial test section pressure was set at $P_{1}=1 \mathrm{~atm}$. Since, under these conditions, the convective flow is initially supersonic relative to the drop, one notes the presence of a stand-off bow shock and several shocks off the wake region. As the drop is accelerated, however, the Mach number of the flow relative to it decreases and the detached shock stand-off distance is observed to increase until the sonic condition is reached and the bow shock disappears.

The streak photographs which were collected for both subsonic and supersonic flow conditions all clearly demonstrated the continuous nature of the shattering process. Each photograph revealed, as does Fig. 3, that the displacement, traced out from the motion of the shadow cast by the forward stagnation point, is a smooth, continuously varying function of time. In other words, no abrupt changes in the local shape of the displacement traces are discernible. On the basis of these observations, then, it seems reasonable to conclude that both the droplet mass and frontal area are also smooth functions of time, because if they were otherwise, one would expect to observe discontinuities in the shape of the displacement curve. The results of these experiments, therefore, do not completely confirm those of Nicholson [12] who reported a discontinuity in his displacement data which was interpreted as a sudden increase in droplet acceleration resulting from an instantaneous change in mass attributable to the breakup.

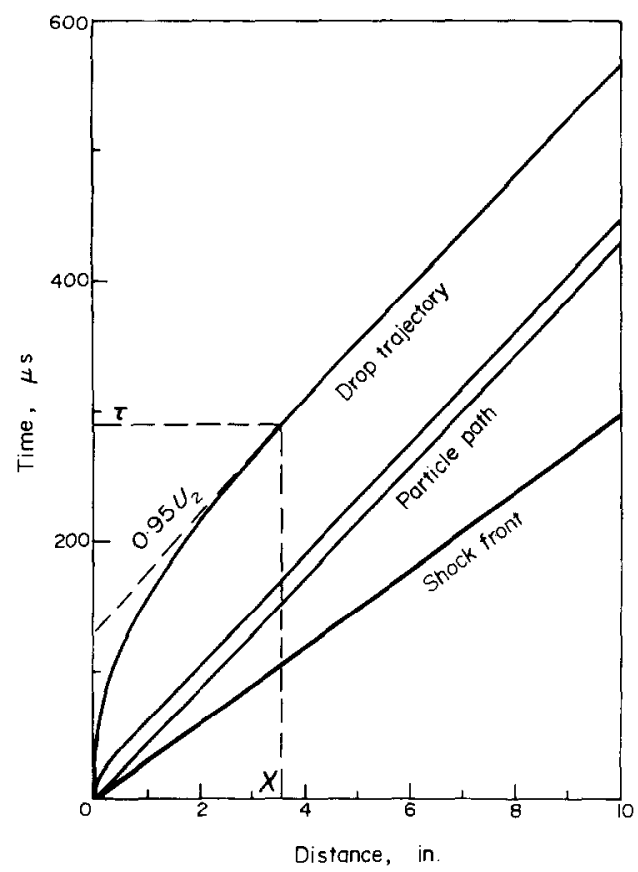

Fig. 4. Atomization of $1100 \mu$ droplet when $M_{S}=2 \cdot 5$.

A tracing of a streak photograph is presented in Fig. 4 to show the displacement $(x)$ and time $(t)$ scales, and to identify the particle path, the drop 
trajectory, and the point $(\chi, \tau)$ at which the local slope of the displacement curve is equal to 95 per cent of the convective flow velocity, $U_{2}$, behind the shock front. It is of interest to note that the material which is initially removed from the drop surface is accelerated almost instantaneously to the particle velocity behind the wave front, thus giving irrefutable evidence of the small size of these particles. For example, assuming that the tiny particles are spherical with $C_{D} \simeq 1-3$, then their size, calculated [10] using data from Fig. 3, is found to be approximately $10-2 \mu$ dia., respectively. The general consensus $[5,8,10]$ on this point is that the higher the initial relative velocity between the gas stream and the droplet surface the smaller will be the liquid particles into which a droplet is ultimately atomized.

Some typical displacement results obtained from the streak photographs are shown in Fig. 5. The points at which the local slopes of the displacement curves are equal to $0.95 U_{2}$ are

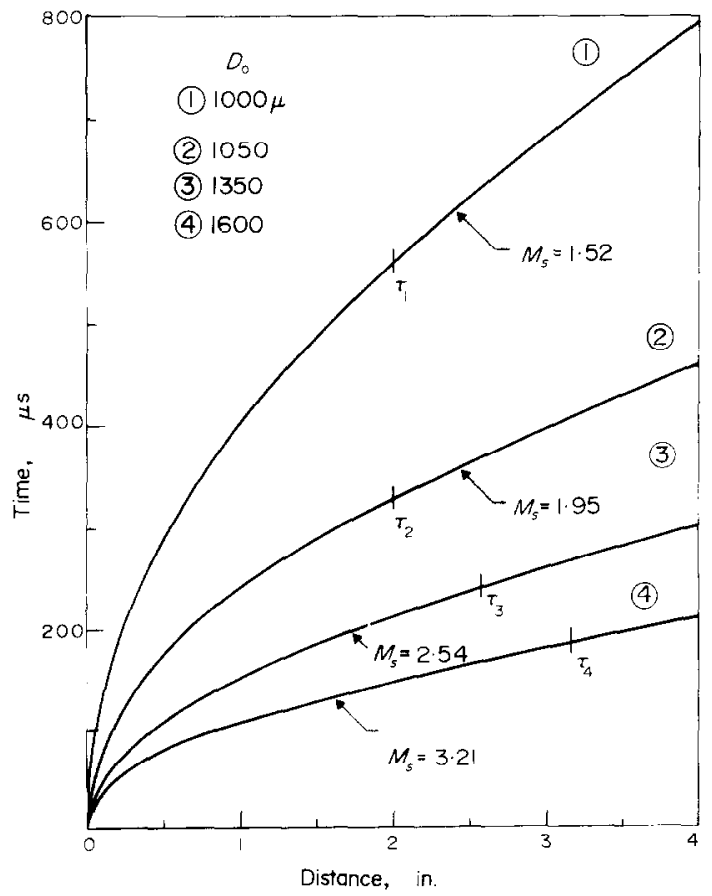

FIG. 5. Displacement data from streak photographs. designated as $(\chi, \tau)$. The initial driven section pressure for all of the data in Fig. 5 was $P_{1}=$ $1 \mathrm{~atm}$. For additional results at lower initial pressures, the reader is referred to [10] and [13]. If these data are replotted in terms of the dimensionless coordinates $[10,11](\bar{X}, \bar{T})$, then we obtain the results shown in Fig. 6. One observes that the data collapse into a system of similarity

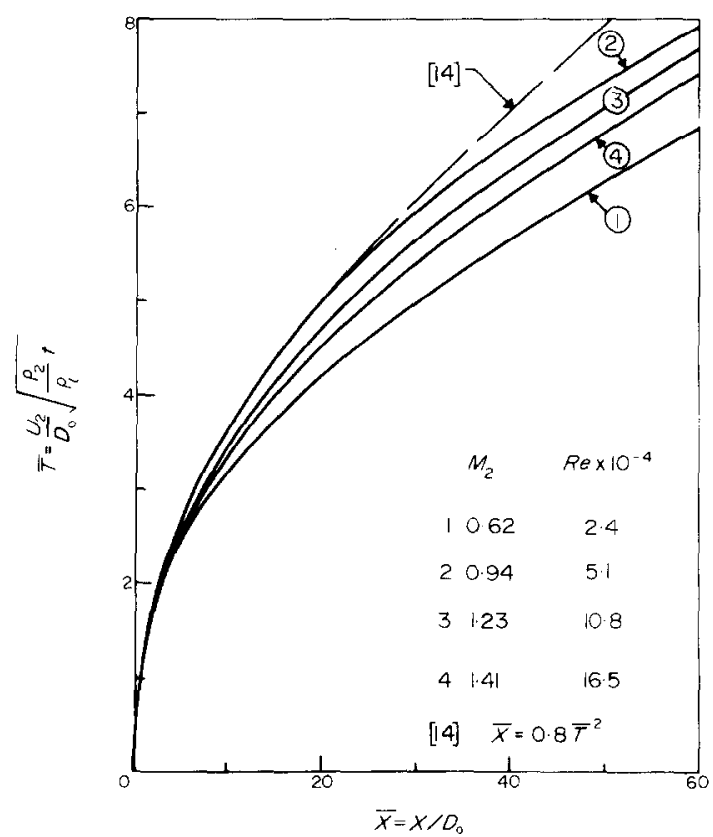

FIG. 6. Dimensionless displacement.

curves which appear to have some parametric dependence on the convective flow Mach number. An adequate physical explanation for the effect of the Mach number on the displacement is complicated by the complex nature of the shattering phenomenon. Not only is the drop shape changing rapidly with time, thus altering the external pressure field around it [17], but the surface is being simultaneously stripped away which consequently reduces its mass. The coupled effects, therefore, of a changing drag and a diminishing mass are manifest in the nondimensional displacement history, and any hope of being able to separate the two, for the 
purpose of giving a satisfactory rational explanation for the Mach number effect, seems very slight indeed. The results of Reinecke and McKay [14] are also shown in Fig. 6 where it can be seen that the agreement is good when the Reynolds number is approximately $5 \times 10^{4}$.

A comparison of the streak and image converter data leads to an important conclusion regarding the definition of a quantitative breakup criterion. For example, one observes in Fig. 7 that the local slope of the streak curves, in the

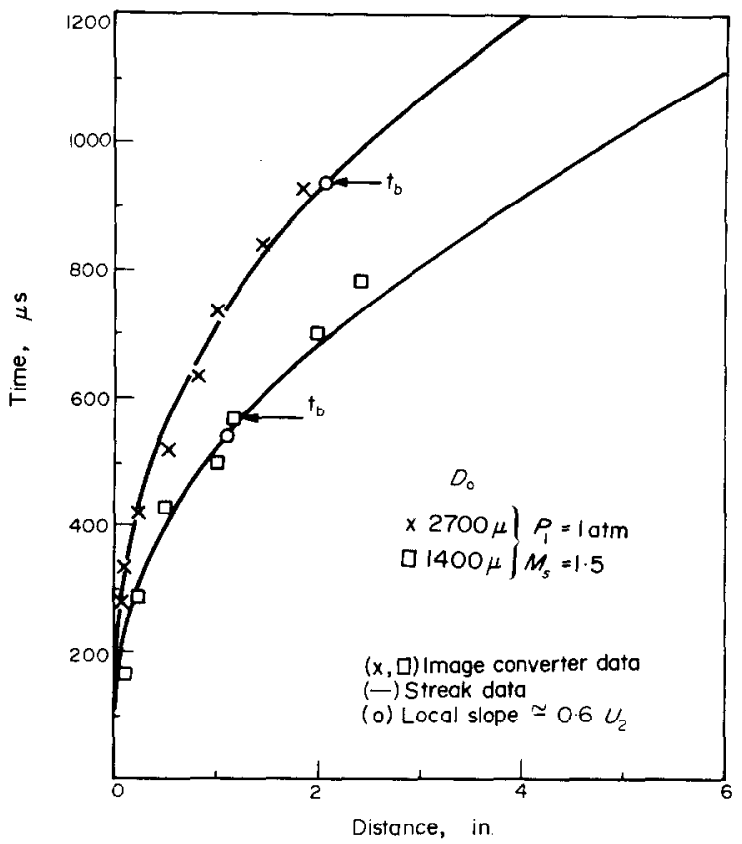

FIG. 7. Comparison of streak and image converter data.

neighborhood of $t_{b}$, is approximately equal to $0.60 U_{2}$. The breakup time, $t_{b}$, was determined from an assessment $[10,11]$ of the image converter photographs. In other words, by the time the droplets have been accelerated to achieve a speed approximately equal to $60 \mathrm{per}$ cent of the convective flow velocity, they are completely disintegrated. The observation of this fact leads one to consider the possibility of defining a quantitative breakup criterion based on the local slope approximation.
By adapting and applying this quantitative criterion to the streak data, the corresponding dimensionless breakup time $\left(\bar{T}_{b}\right)$ and distances $\left(\bar{X}_{b}\right)$ can be calculated and compared with those found from the image converter data. The two dimensionless breakup times are plotted in Fig. 8, as a function of the convective flow

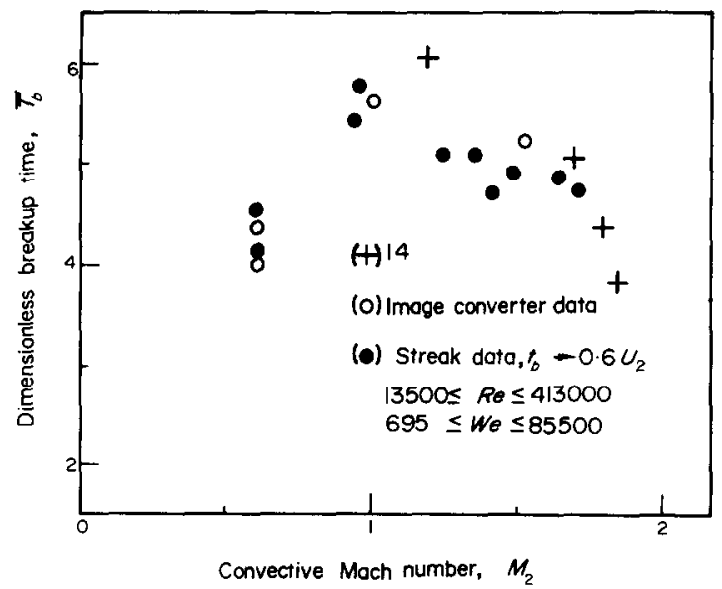

FIG. 8. Comparison of dimensionless breakup times.

Mach number, for a variety of aerodynamic conditions. The indication is that the two sets of data agree quite well with one another both in magnitude and in distribution with $M_{2}$. The conclusion to be drawn from Fig. 8 is that the dimensionless breakup time is relatively constant, $\bar{T}_{b} \simeq 5$, over a wide range of drop size

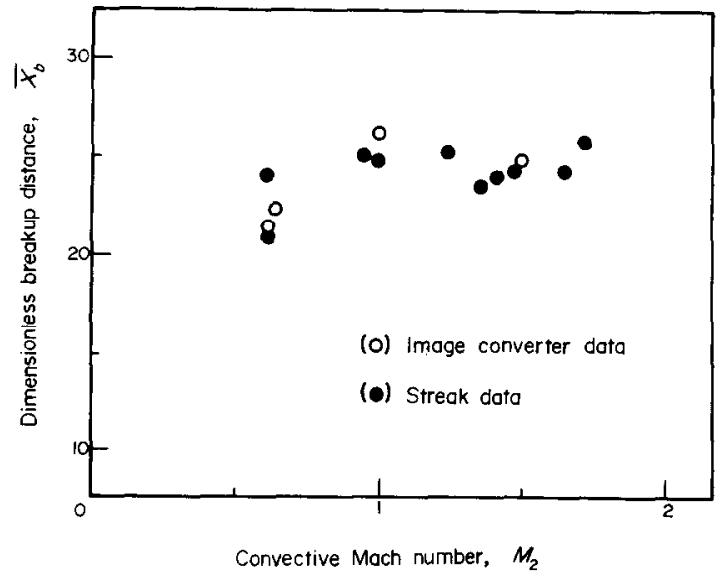

FIG. 9. Dimensionless breakup distance. 
aerodynamic conditions. However, there is some indication to suggest that its value should be slightly lower when $M_{2}<1$ and a bit higher when $M_{2} \geqslant 1$. Again, the results from [14] are shown for comparison with those of the present study. Some of the disparity at the higher convective Mach numbers is attributable to the different definition of breakup time used in the two studies.

The corresponding dimensionless distances are plotted vs. $M_{2}$ in Fig. 9 where one notes from the variation that $\bar{X}_{b}$ is approximately a constant except at the subsonic end of the distribution where it falls off somewhat from the mean value of $\bar{X}_{b} \simeq 25$.

\section{CONCLUSIONS}

Under the conditions of high Weber number the atomization of a liquid drop in a convective gas stream begins almost instantaneously following its exposure to the flow. Calculations made of the size of the tiny particles into which a droplet is atomized indicate that they are on the order of 1-10 $\mu$ dia. A comparison of the data collected in the present study with that obtained previously reveals that the droplets are completely atomized by the time they have been accelerated up to a velocity equal to 60 per cent of the convective flow speed. The time required for a droplet to become completely atomized is given by $t_{b} \simeq 5\left[D_{0} / U_{2}\right]\left[\rho_{l} / \rho_{2}\right]^{\frac{1}{2}}$ and the distance it is translated by the flow in the course of being shattered is $x \simeq 25 D_{0}$.

\section{ACKNOWLEDGEMENTS}

The Authors would like to take this opportunity to acknowledge the support of the National Aeronautics and Space Administration under contract NASr $54(07)$ and NASA Grant NGL 23-005-336.

\section{REFERENCES}

1. E. Giffen and A. Muraszew, The Atomization of Liquid Fuels, pp. 1-35. John Wiley, New York (1953).

2. G. K. BATCheloR and R. M. DAVIES, The mechanics of drops and bubbles, Surveys in Mechanics, pp. 162 215. Cambridge University Press (1956).

3. J. O. Hinze, Critical speeds and sizes of liquid globules, Appl. Sci. Res. A1, 273-288 (1948).

4. A. C. Merrington and E. G. Richardson, The breakup of liquid jets, Proc. Phys. Soc.. Lond. 59, 1 (1947).

5. W. R. LANE, Shatter of drops in streams of air, ind. Engng Chem. 43, 1312-1317 (1951).

6. A. R. HANSON, E. G. DOMICH and H. S. ADAMS, Shock tube investigation of the breakup of drops by air blasts, Physics Fluids 6, 1070-1080 (1963).

7. A. A. Buzukov, The breakup of drops and a fluid stream by an air shock wave, $f$. Appl. Mech. Tech. Phys. No. 2, $154-158$ (1963).

8. E. A. RoJec Photographic presentation of shear-type droplet breakup, Rocketdyne Res. Rept. 63-39, North American Aviation. Inc., Canoga Park, California (Nov. 1963).

9. H. Wolfe and W. Anderson, Aerodynamic break-up of liquid drops, Paper SP70, Amer. Phys. Soc. (April 1965).

10. A. A. Ranger, The aerodynamic shattering of hiquid drops, Ph.D. Dissertation, The University of Michigan (1968),

11. A. A. Ranger and J. A. NrCholls, Aerodynamic shattering of liquid drops, ALAA JI7, 285-290 (1969).

12. J. W. Nicholson, Drop breakup by airstream impact, Proc. Second Meersburg Conf. Rain Erosion and Allied Phenomena, Vol. 1, pp. 262-297 (August 1967).

13. A. A. RANGER and J. A. Nicholls, Water droplet breakup in high speed airstreams, Proc. 3rd Int. Conf. Rain Erosion and Allied Phenomena, R.A.E. Farnborough, England (August 1970).

14. W. G. REINECKE and W. L. MCKAY, Experiments on water drop breakup behind Mach 3 to 12 Shocks, Sandia Corporation, Res. Rept. Sc-CR-70-6063, Albuquerque, New Mexico (1969).

15. E. K. Dabora, Production of monodisperse sprays. Rev, Scient. Instrum. 38, 502-506 (1967).

16. G. I. TAYLOR, The shape and acceleration of a drop in a high speed air stream, The Scientific Papers of $G$. $I$. Taylor, edited by G. K. BATCHeLoR, Vol. III, pp. 457464. University Press, Cambridge (1963).

17. A. A. RANGER and J. A. Nicholls, Shape and surrounding flowfield of a drop in a high-speed gas stream, $A I A A J 18,1720-1722(1970)$.

\section{ATOMISATION DE GOUTTES LIQUIDES DANS UN COURANT CONVECTIF GAZEUX}

Résumé-Des nouveaux résultats expérimentaux sont présentés pour l'atomisation de gouttes liquides par un courant d'air à grande vitesse. On décrit une série d'expériences dans laquelle on introduit des gouttes d'eau, de diamètre variant de 1000 à $2700 \mu$, dans la section test d'un tube de choc et on assure leur intéraction avec l'écoulement convectif établi par le passage d'une onde de choc. Un système de caméra à tambour est employé afin d'obtenir un ensemble de photographies du processus d'atomisation à partir duquel ont été déterminés le temps de rupture, la distance de rupture, et la taille ultime de la particule atomisée. Les expériences couvrent un domaine du nombre de Wéber tel que $0,7.10^{3} \leqslant W e \leqslant 85,5.10^{3}$. 


\title{
ATOMISIERUNG VON FLÜSSIGKEITSTRÖPFCHEN IN EINEM KONVEKTIVEN GASSTROM
}

Zusammenfassung-Es werden neue experimentelle Ergebnisse angegeben für die Atomisierung von Flüssigkeisirüpfchen in cinem Luftstrom mit hoher Geschwindigkeit. Ein Reihe von Versuchen wird beschrieben, bej denen Wassertröpfehen mit 1000 bis $2700 \mu \mathrm{m}$ in den Testabschnitt eines Strossrohres eingeführt und zur Wechselwirkung mit einer Konvektionsströmung gebracht werden. Dies wird mit einer Stosswelle erreicht. Eine rotierende Trommelkamera wurde entwickelt, um eine Reihe von Blitzaufnahmen des Atomisierungsprozesses zu erhalten. Daraus werden Zeit und Weg bestimmt, die ein Tröpfchen zu scincr Auflösung benötigt, cbenso dic Stclle, an der das lctztc Tröpfchen atomisiert wurdc. Dic Experimente überdeckten einen Bereich der Weber-Zahl von $0,7 \cdot 10^{3}$ bis $85,5 \cdot 10^{3}$.

\section{РАСПЫЛЕНИЕ КАПЕЛЕК ЖИДКОСТИ В КОНВЕКТИВНОМ ГАЗОВОМ ПOTOKE}

\begin{abstract}
Аннотация-Приводятся новые әкспериментальные данные по распылению капелек жіпкости высокоскоростным воздушным потоком. Описывается целый ряд әксперимептов, когда в рабочую часть ударной трубы вводятся капельки жидкости диаметром от 1000 до $2700 \mu$, ноторые взаимодействуют с конвективным потоком, создающимся ирін прохожіннии фронта распространяющейся ударной волны. Для получения 11: тосшых фотографий процесса распыления, по которому определялось время диспергиролапи, расстояпн, на котором происходит дробление и максимальный размер расыыляюшихся частиц, нспользовалась система с барабанным фотоаппаратом. эксперименты ироводились в диапазоне чисел Вебера $0,7 \times 10^{3}<W e<85,5 \times 10^{3}$.
\end{abstract}

